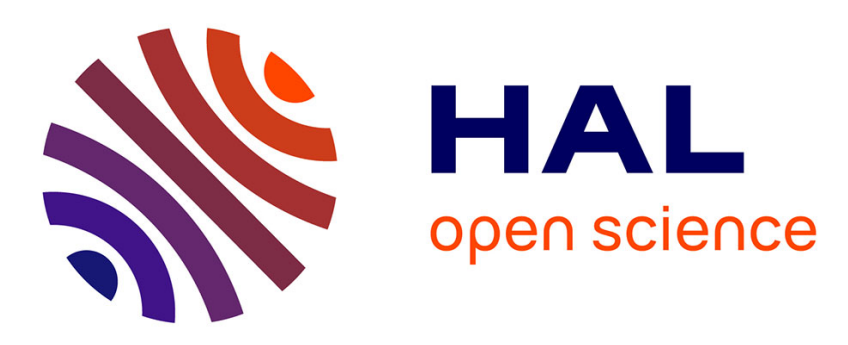

\title{
Kennedy disease (X-linked recessive bulbospinal neuronopathy): A comprehensive review from pathophysiology to therapy \\ G. Querin, G. Sorarù, P.-F. Pradat
}

\section{- To cite this version:}

G. Querin, G. Sorarù, P.-F. Pradat. Kennedy disease (X-linked recessive bulbospinal neuronopathy): A comprehensive review from pathophysiology to therapy. Revue Neurologique, 2017, 10.1016/j.neurol.2017.03.019 . hal-01520284

\section{HAL Id: hal-01520284 \\ https: / hal.sorbonne-universite.fr/hal-01520284}

Submitted on 10 May 2017

HAL is a multi-disciplinary open access archive for the deposit and dissemination of scientific research documents, whether they are published or not. The documents may come from teaching and research institutions in France or abroad, or from public or private research centers.
L'archive ouverte pluridisciplinaire HAL, est destinée au dépôt et à la diffusion de documents scientifiques de niveau recherche, publiés ou non, émanant des établissements d'enseignement et de recherche français ou étrangers, des laboratoires publics ou privés. 
Kennedy disease (X-Linked recessive Bulbospinal Neuronopathy): a comprehensive review from pathophysiology to therapy.

${ }^{1}$ Giorgia Querin, ${ }^{2}$ Gianni Sorarù, ${ }^{3}$ Pierre-François Pradat.

1) Sorbonne Universités, UPMC Univ Paris 06, CNRS, INSERM, Laboratoire d'Imagerie Biomédicale, Paris, France.

2) Department of Neurosciences, University of Padova, Padova, Italy.

3) APHP, Hôpital Pitié-Salpêtriere, Département des Maladies du Système Nerveux, Centre référent SLA, Paris, France.

Correspondance to: Pierre-François Pradat. Département de Neurologie. Hôpitaux Universitaires PitiéSalpêtrière/Charles Foix, Assistance Publique-Hôpitaux de Paris, F75-013 Paris, France.

Tel: +33 142162471, Fax: +33 142162735

e-mail: pierre-francois.pradat@psl.aphp.fr

Acknowledgments: the authors thank AFM-Téléthon, Téléthon Biobank, Institut pour la Recherche sur la Moelle épinière et l'Encéphale (IRME), Association pour la Recherche sur la SLA (ARSla) and the University of Padova for their research support. 


\title{
Kennedy disease (X-Linked recessive Bulbospinal Neuronopathy): a comprehensive review from pathophysiology to therapy.
}

\begin{abstract}
Kennedy's disease, also known as spinal and bulbar muscular atrophy (SBMA), is a rare, adult-onset, Xlinked recessive neuromuscular disease. It is caused by expansion of a CAG repeat sequence in exon 1 of the androgen-receptor (AR) gene, encoding a poly-glutamine (polyQ) tract. Poly-Q-expanded AR accumulates in nuclei and initiates degeneration and loss of motor neurons and dorsal root ganglia. The disease has been retained to be a pure lower motor neuron disease for a long time, but recently the presence of important hyper-Creatine-Kinase-emia and of myopathic alterations on muscle biopsy has suggested the presence of a primary myopathy underlying a wide proportion of clinical manifestations. The disease, that affects male adults, is characterized by muscle weakness and atrophy localized proximally in the limbs and by bulbar involvement. Sensory disturbances are associated to the motor phenotype but may be subclinical. The most frequent systemic symptom is gynecomastia related to androgen insensitivity, but other abnormalities, such as heart rhythm and urinary disturbances, have also been reported. The course of the disease is slowly progressive with normal life expectancy. The diagnosis of SBMA is based on genetic testing, with 38 CAG repeats retained to be pathogenic. Even though several therapeutic attempts have been made in mouse models, no effective disease modifying therapy is available but symptomatic therapy is beneficial for the management of weakness, fatigability and bulbar symptoms.
\end{abstract}

Keywords: Kennedy's disease, SBMA, muscular involvement, systemic symptoms, diagnosis, clinical trials. 


\section{Introduction}

Spinal and Bulbar Muscular Atrophy (SBMA), also known as Kennedy's Disease (KD), is an X-linked recessive, adult onset, slowly progressive, lower motor neuron disease (MND) characterized by limb and bulbar muscle atrophy, weakness and fasciculations [1]. The disease is caused by a CAG repeat expansion in the first exon of the androgen receptor gene (AR), with a number of CAG repeats bigger than 38 retained to be pathogenic. It affects adult males and the CAG repeat size correlates inversely with disease onset but not with disease progression or severity [1].

In this article, we will review the main epidemiological, clinical and laboratory findings as well as current treatment options for the disease together with the pathophysiological aspects and the directions in therapeutic research.

\section{Epidemiology}

SBMA is a rare disease with an estimated incidence of 1 case over 400.000 per year [2] and a multiple founder effect across the world [3] [4]. For this reason, the prevalence of the disease in various areas can be widely different, with isolated regions, such as the Vaasa region in Western Finland, presenting with particularly elevated numbers of affected patients [5]. Moreover, SBMA is often not properly diagnosed and confused with other neuromuscular diseases, leading to probable underestimation of the real prevalence.

The age at onset is between 30 and 50 years [6] and the progression of the disease is so slow that the life expectation barely decreases [7] and is calculated at 71.3 years of age, with average disease duration of 27.3 years [8].

\section{Clinical features}

Neuromuscular phenotype. SBMA is a lower MND with slowly progressive phenotype. Muscle weakness is usually the main clinical feature of the disease and occurs in $97 \%$ of the cases. It usually appears at age 3540 and a correlation between CAG-repeats number and age at onset has been noted [9], although poly-Q tracts does not seem to affect disease progression [10], [1].

The appearance of muscle weakness has been classically considered as the sole onset manifestation. Lower limb weakness is indeed the most common presenting symptom (86.7\%), followed by upper limb weakness 
(22.2\%) [1]. However, more recently, it has been highlighted that other slighter symptoms are often present long time before the onset of muscular weakness. More specifically, these symptoms may be hand tremors, muscular cramps, myalgias, breast enlargement, premature exhausting during physical exercise and feet numbness [11].

Hand tremor is often the first manifestation noted by the patients and appears at a median age of 35 years, followed by muscle weakness at a median age of 43 . The sequential use of walking aids (handrail, cane, frame, and wheelchair), bulbar-related symptoms (dysarthria and dysphagia), and erectile dysfunction are reported between the ages of 50 and 60 years. Since lower limbs' proximal muscles are predominantly affected, a particular feature of SBMA is the difficulty in stairs climbing and in rising up from a chair [11]. Hand tremor is usually a postural high frequency tremor possibly resulting in impairment of daily activities, such as writing, cutting or eating [12] [13]. Postural leg tremor has been described in a small number of patients and in a single study it seems to correlate with the number of CAG repeats in the AR gene [14].

Reduced effort tolerance and fatigability are reported by SBMA patients in every stage of the disease and can be limiting in the activities of daily living (ADL). Involvement of the brainstem motor nuclei results in bulbar muscle weakness [15], which is a typical feature of SBMA. Though bulbar involvement usually follows limb involvement, it is occasionally the presenting symptom. If there is weakness of the masseter muscles the mouth may hang open (jaw drop) and may be tremulous [16] [17]. The tongue usually shows fasciculations and irregularities at the edges or deep furrowing in the midline due to wasting (Figure 1). Tongue atrophy might be associated with difficulty in chewing, vocal cord paresis resulting in dysarthria or dysphonia, and pharyngeal paresis leading to dysphagia [18]. The voice becomes nasal because of palatal weakness. Some patients may develop laryngospasm, which pathogenesis in still not completely clear [19] [20]. Swallowing dysfunction is found in $80 \%$ of the cases and is characterized by incomplete food bolus clearance through the pharynx [21]. Spontaneous or voluntary contractions of the perioral muscles may elicit twitching movements of the chin, also known as "quivering chin". Respiratory muscles can be progressively involved, however an overt respiratory failure is uncommon [9].

AR aggregates accumulate not only in spinal cord and brainstem motor neurons, but also in the dorsal root ganglia, resulting in decreased vibratory sensation and loss of sensory functions in the extremities [22]. The reduction of vibratory sense, associated with motor impairment, leads to weak or absent deep tendon reflexes 
and could be related to an alteration of sensory fibers together with possible autonomic dysfunction [23]. The presence of sensory neuropathy may also be associated with neuropathic pain mainly localized distally in lower limbs associated with frequent feet numbness and tingling, which has been reported in up to 58\% of the patients [1].

Systemic symptoms. SBMA is not only a neuromuscular disease: a wide clinical spectrum has been reported, probably due to the fact that AR expression is diffuse in various regions of the nervous system and in non-neural tissues as well [24] [25]. For this reason, other testosterone target tissues can be involved in the disease and non-neurological symptoms are present in the majority of the patients. Endocrinological disturbances are frequent although serum testosterone levels are usually normal. They predominantly include gynecomastia and reduced fertility due to testicular atrophy, azoospermia, oligospermia, erectile dysfunction, or reduced libido [26] [27]. Gynecomastia is probably the most common non-neurological manifestation and can present at a very young age. Because of the late onset, infertility and reduced libido may not be appreciated readily but many patients claim having difficulty conceiving [28].

Abdominal obesity, dyslipidemia, liver dysfunction and glucose intolerance are also detected in some patients, that frequently develop a complete metabolic syndrome [29] [30]. While gynecomastia and other symptoms of androgen insensitivity appear to result from the partial loss of AR function, the remaining nonneuronal symptoms are likely due to toxicity of the pathogenic AR in these tissues [24].

Recently it has also been reported an increased incidence of Brugada's syndrome in a Japanese cohort of SBMA patients (more than $10 \%$ of the observed patients) with some sudden deaths (2 out of 144 observations). The pathophysiology of Brugada syndrome in the context of SBMA has not been completely explained but intranuclear inclusions of mutated AR have been demonstrated in myocardial cells [31]. Anyway, the only study considering the presence of Brugada's syndrome in a Caucasian SBMA population did not clearly confirm an increased prevalence [30]. At the same time, the presence of a primary cardiomyopathy has been ruled out [32].

Recently, urological involvement has been described: almost $40 \%$ of the patients may present moderate signs and symptoms of lower urinary tract obstruction in absence of prostatic hypertrophy, with some of them needing an indwelling bladder catheter [30]. The precise mechanism is still not clear but it is probably 
related to androgen insensitivity. These findings are reminiscent of animal models of SBMA since mice frequently die after renal failure due to urinary obstruction [33].

Neuropsychological involvement. Extensive accumulation of mutant AR in the brain of SBMA patients [24] has been demonstrated, and recent studies have focused on the morpho-functional consequences of SBMA on the central nervous system. Neuropsychological involvement has been investigated in some small studies with partially contrasting results [34] [35] [36] pointing to a possible frontal lobe dysfunction. Soukup et al. [37] conducted the first systematic study finding a predominantly prefrontal pattern of cognitive dysfunction, in terms of subtle deficits in executive processing, and an altered short and long-term memory, justified by the frontal lobe's involvement in organizing and processing memory content. From a clinical viewpoint, it is common for patients with SBMA to have peculiar psychological characteristics such as diffidence, marked emotional sensitivity and concentration problems. Such observations are supported by the evidence of an alteration in theory of mind functions supporting empathy, which is related to complex frontal functions [38]. Magnetic resonance and electrophysiological studies [39] showed subclinical abnormalities in the primary motor cortex and other frontal areas of the brain in SBMA patients. More recently, magnetic resonance imaging (MRI) studies using voxel-based morphometry (VBM) and diffusion tensor imaging (DTI) reported widespread white matter and subtle gray matter changes in the frontal regions [40]. Further research [41] found widespread white matter changes in the corticospinal tract and in the limbic system, while another study [42] described multifocal white matter changes, mainly in the brainstem. A recent positron emission tomography (PET) [43] study also identified hypometabolism in the frontal regions, in ten patients with SBMA.

\section{Diagnosis of SBMA}

The gold standard for SBMA diagnosis is the genetic test that estimates CAG expansion number in the AR gene, considering more than 38 repeats to be pathologic [44].

Analysis of family history is important for the preliminary selection of patients who should undergo genetic analysis even if the presentation is often sporadic. Symptoms can be unspecific for many years after disease onset, often resulting in a significant diagnostic delay. Some non-neural features, such as gynecomastia, can be fundamental in orientating the diagnostic process. The increase of creatine phosphokinase (CPK) levels 
may also be suggestive since it is found in almost all patients with levels that can be very high, until 38 fold the normal value, and decrease over time with the progression of the disease [10] [45]. Some endocrinal findings, for instance glucose intolerance or dyslipidemia, in association with lower motor neuron abnormalities, can support the diagnosis of SBMA. The diagnosis is often suspected on an electromyographic (EMG) examination performed in the routine work up of a motor neuron disease. It shows a chronic neurogenic pattern with fasciculations that extend beyond the territories affected by weakness [4]. The diminution of amplitude of the sensory action potentials, in the context of a MND, is suggestive of SBMA. Sensory abnormalities are found in $72 \%$ to $100 \%$ of SBMA patients $[6,10,11]$.

In addition, muscle biopsies are sometimes performed, mainly when a myopathy is initially suspected. Signs of neurogenic atrophy have been described in all the patients: type I and II fibres aggregation, target fibres, atrophic fibres and subsarcolemmal nuclei clumping. On the other hand, myopathic abnormalities are frequently present, such as a wide variability in fibres size $(4-200 \mu \mathrm{m})$, hugely hypertrophic fibres, spread basophilic fibres and necrotic fibres with vesicular nuclei. Myopathic alterations are more incident in patients with a higher grade of disability [46].

Differential diagnosis. Reaching a diagnosis of SBMA may be difficult at the beginning of the disease since symptoms are often blurred and unspecific. The most frequent misdiagnosis is Atrophic Lateral Sclerosis (ALS), which may present with limbs and bulbar weakness and with evidence of diffuse muscle denervation at EMG. However, ALS presents usually a faster progression, with the development of respiratory failure, and is typically associated with upper motor neuron involvement. Furthermore, endocrine and sensitive abnormalities are not found in ALS. Spinal Muscular Atrophy (SMA) type III and IV may also be misdiagnosed for SBMA but usually symptoms appear at younger age, sensitive or endocrine abnormalities are not present and the transmission is autosomal recessive. The presence of high serum CK levels together with proximal muscle weakness may lead to a diagnosis of myositis, polymyositis, metabolic myopathy or other primary myopathies. Combination of bulbar involvement and limbs weakness could also lead to the diagnosis of myasthenia gravis, while the neuropathic involvement might be similar to that of chronic inflammatory neuropathies or some hereditary sensory-motor neuropathies. Complete differential diagnosis is summarized in table 1. 


\section{Pathogenesis}

SBMA is an X-linked genetic disorder and a CAG-expansion disease. The polyglutamine-expanded AR (polyQ-AR) leads to cell death, especially in spinal cord and brainstem motor neurons. Anyway, the precise mechanism of motor neuron degeneration and muscle atrophy is not yet completely clear and probably many different pathways are involved (Figure 2). Under normal conditions, upon binding of its ligands testosterone and dihydrotestosterone, AR is translocated from the cytosol into the nucleus, where it plays an important role in the regulation of gene expression. In SBMA, alteration of this pathway is retained to be a major pathogenic process [47] [48], associated with nuclear accumulation of the pathogenic protein [24], which may interfere with cellular functions. Nuclear inclusions and diffuse nuclear accumulation of polyQ-AR are histological markers of the disease and are found not only in motor neurons, but also in different regions of nervous system and in several non-neural cells (liver, cutis, kidney's proximal tubules, testis, prostate and scrotal skin) [24] [49] [25]. Cytoplasmic diffuse accumulation of the mutated protein is possible as well but its role in disease pathogenesis in not completely clear and its extend seems to be tissue-dependent [24]. The inclusions show a granular aspect with a fibrillary pattern and they do not present any kind of membranes. Inclusions containing mutant AR are usually positive for ubiquitin, supporting the hypothesis that toxicity could be due to an abnormal response to the polyQ tract that escape degradation through the proteasome. Moreover, several proteins are detectable in the inclusions, such as the chaperones Hsp70 and Hsp90, CREB Binding Protein (CBP) and other transcription factors. Loss of function of these proteins when they are sequestered in the inclusions could contribute to pathogenesis of the disease [50] [51] [52]. It is not completely clear which hypothesis is the correct one and whether protein aggregation is a toxic or a protective mechanism [53]. Together with aggregates formation, mitochondrial abnormalities and axonal transport alterations may participate to disease pathogenesis [54] [55].

Muscle matters in SBMA. Traditionally, SBMA has been viewed as a cell-autonomous, primary motor neuron disease, where neuronal death is, at least in part, due to a toxic gain-of-function in the mutant protein. More recently, because of high CPK serum levels [56] [57], which are higher than expected for a purely neurogenic disease, together with the presence of myogenic changes in muscle biopsy from patients, the hypothesis of a primary myopathic component contributing to the development of pathology has been put forward [46] [58] (Figure 3). Evidence of mixed neurogenic and myopathic processes has also been reported 
in mouse models of SBMA. Histopathological analysis of muscle tissues from transgenic and knock-in mice expressing polyQ-AR revealed both neurogenic and myopathic features [59] [49] [60] [33]. It is noteworthy that in the knock-in mouse model of SBMA, muscle pathology is evident prior to the onset of spinal cord pathology [61]; strongly supporting the view that muscle is a primary target of polyQ-AR toxicity [62].

Androgens have remarkable anabolic effects on skeletal muscle. Reduction of testosterone levels in the serum results in a decrease in muscle strength with concomitant increase in fat body mass, while testosterone administration both in healthy individuals and in hypogonadal men results in enhanced muscle strength and size, increased lean body mass, and improved performance. Interestingly, satellite cells express the highest levels of AR in skeletal muscle [63]. Satellites cells are the main target for polyQ-AR toxicity and androgens have been shown to promote proliferation and differentiation, which may account for the hypertrophic effect of androgens on muscle [64]. Conversely, it is possible that androgens trigger toxic response in satellite cells expressing polyQ-AR contributing to muscle deterioration in SBMA [65]: while androgens and AR have remarkable hypertrophic effects on skeletal muscle, they have detrimental effects in SBMA muscle. PolyQ expansion in AR has been proposed to cause toxicity in muscle through altered gene expression [66]. The SBMA phenotype elicited by overexpression of either wild-type or polyQ-AR in mice is associated with deregulation of gene transcription in muscle. Another important pathway of toxicity in SBMA muscle is alteration of RNA splicing [67]. Expression of polyQ-AR in the muscle of SBMA mice alters RNA processing in a hormone-dependent fashion. It remains to be established how these toxic pathways contribute to disease pathogenesis and whether the changes in gene expression due to altered gene transcription or altered RNA processing are primary or secondary events.

Damage to motor neurons can also result from non-cell-autonomous toxic processes occurring in other cell types, such as muscle and glial cells. These cells provide motor neurons with trophic support, which is essential for motor neuron maintenance in adulthood. Neurotrophins and growth factors are two classes of trophic factors that protect neurons by activating signaling pathways that prevent initiation of apoptotic pathways and promote activation of pro-survival pathways. The expression of neurotrophins and growth factors is altered in mouse models of SBMA [68]. This observation highlights the idea that altered trophic support to motor neurons from neighboring tissues may be responsible for non-cell-autonomous damage in SBMA. IGF-1 is a powerful pro-survival factor for many different cell types, including neurons. IGF-1 
promotes sprouting, axonal growth, and survival of embryonic motor neurons in both normal and pathological conditions [69]. IGF-1 protects MN-1 cells expressing polyQ-AR from death [70]. In addition to direct effect on motor neurons, IGF- 1 can have positive effects on muscles. IGF-1 has been shown to induce muscle hypertrophy and to inhibit muscle atrophy [60] through activation of phosphoinositide 3kinase/Akt pathway. IGF-1/Akt signaling promotes muscle hypertrophy by inducing novel protein synthesis through inhibition of glycogen synthase kinase $3 \mathrm{~b}$ and activation of mammalian target of rapamycin (mTOR) [71]. The contribution of these pathways to SBMA pathogenesis remains to be elucidated. Recently, Lieberman's group has shown that there is an induction of the unfolded protein response in the muscle of both patients and mouse models of SBMA, and that this stress response leads to the activation of macroautophagy and to muscle atrophy, further supporting a pathogenic role for autophagy in SBMA muscle [72]. The mechanism through which IGF-1 protects SBMA mice from neurodegeneration involves activation of Akt and phosphorylation of polyQ-AR, an event that leads to mutant protein degradation by the proteasome. Besides a direct role on muscle, muscle-specific overexpressionof IGF-1 may stimulate the secretion of growth factors and neurotrophins from muscle, which in turn can have beneficial effects on motor neurons. Nonetheless, this finding indicates that muscle represents an important therapeutic target for SBMA and supports the idea that muscle damage is critical for disease pathogenesis.

\section{Therapy}

\section{Symptomatic treatment}

Since a disease modifying treatment for SBMA does not yet exist, only a palliative approach is possible, that is mainly based on rehabilitation and symptomatic pharmaceutical treatments. Genetic counseling is warranted for patients and couples programming a pregnancy. Assisted fecundation therapies may be applied if reduced fertility is present.

In order to preserve motor functions and autonomy as long as possible, regular aerobic physical activity and physiotherapy are usually recommended. Ambulation may be helped with assisted devices and sometimes a wheel chair may be needed. Muscle cramps are frequent, may be persistent and influence patients' quality of life. Symptomatic treatment with quinine sulfate is usually prescribed and may be efficient even if it has not 
been evaluated by therapeutic trials. The treatment of neuropathic pain is based on the classic drugs used in this indication, e.g. antiepileptics and amitriptyline.

Speech therapy aims at improving voice modification and dysarthria. Behavioral measures can be instituted to reduce the risk of aspiration in patients presenting with significant dysphagia. Nutritional control is useful for weight control. Since bulbar symptoms remain relatively moderate, the patients do not need enteral feeding or speech augmentation devices during the course of their disease [7]. Aspiration pneumonia, that is a predominant cause of death and hospitalization in SBMA patients [10], should be treated proactively with antibiotics. Although diaphragmatic weakness remains absent or moderate in the majority of patients, noninvasive ventilation may be indicated in rare cases [7].

Since metabolic involvement can ben harming with significantly increased cardio-vascular risk, regular biochemical and cardiological monitoring is warranted in order to establish specific treatment for dyslipidemia, heart pathology, diabetes and high blood pressure when needed.

\section{Experimental treatments}

Several preclinical studies aiming at slowing down disease progression or to improve muscle function have been shown to be beneficial, but none of them univocally demonstrated a positive effect in the translation to clinical trials [73].

Androgen reduction therapy: it is known that SBMA phenotype depends on androgen availability, therefore a therapy that aims to decrease androgens level may be beneficial. In mice models therapy with GnRH analog Leuprorelin was tested, with evidence of reduction of nuclear inclusions [74]. Another approach consists in the use of $5 \alpha$-reductase inhibitors, such as dutasteride. The enzyme is responsible of testosterone conversion in dihysrotestosterone (DHT) that is more potent and consequentially is able to induce a major AR activation in the tissues where it is expressed. Blocking $5 \alpha$-reductase may therefore ameliorate disease progression, however no significant improvements in muscle strength was observed in a clinical trial [75] [76].

Interference with transcriptional and post-transcriptional processes: another therapy attempt has been the use of sodium butyrate, a histone deacetylase inhibitor. In mouse models, its administration was successful, resulting in an increase of weight, muscle strength, movement capabilities and lifespan [77]. 
Furthermore, therapy with microRNA (mirRNA) has been tried for their capabilities to regulate gene expression, augmenting the decay of AR mRNA. It has been demonstrated that they can significantly improve the phenotype of SBMA mice but has never been tested in human patients [78].

Allosteric mediation of polyglutamine expanded AR toxicity: a ligand-induced conformational change of AR is fundamental to stabilize the receptor and promote downstream pathway. Therefore its inhibition, for example using the non-steroid anti-androgen flutamide, may be an ideal target for therapy in SBMA [79] [80]. Although the phenotype does not improve, some benefits are detectable in transgenic mice overexpressing wild type AR, when flutamide is administered at a prenatal stage [62] [81] [66].

The endogenous stress response as a therapeutic target: since intranuclear aggregations are associated with ubiquitin and Hsps, the ubiquitin proteasome system is believed to be involved in degradation of normal and mutant AR [82]. Overexpression of Hsp70 and Hsp40 has been shown to reduce AR aggregation and toxicity in mouse models [83] [84][85]. Moreover, using Hsp inhibitors [86] or co-inducers of the HSR mediated by the transcription factor heat shock factor 1 (HSF1) [87] expression levels of Hsps can be enhanced. Importantly, it was shown that arimoclomol, a co-inducer of the HSR, significantly improved hind limb muscle force and contractile characteristics, rescued motor units, improved motor neuron survival and upregulated the expression of the VEGF in the AR100 mouse model of SBMA [88].

Autophagy-mediated polyglutamine expanded AR degradation: proteins degradation also occurs through the autophagy pathway in polyglutamine diseases [89]. This process is mediated by lysosomes and is linked to the proteasome degradation system. Autophagy can be enhanced through the use for example of rapamycin or trehalose [90] [91]; however it may be unsuccessful in SBMA, because toxic mutant protein is localized in the nucleus [72].

CGRP-mediated toxicity mitigation: a recent study [92] demonstrated that pathogenic AR upregulates the gene encoding calcitonin gene-related peptide (CGRP1). In neuronal cells, overexpression of CGRP1 induces cellular damage via the activation of the c-Jun N-terminal kinase (JNK) pathway, whereas pharmacological suppression of CGRP1 or JNK attenuates the neurotoxic effects of pathogenic AR. Naratriptan, a serotonin 1B/1D (5-hydroxytryptamine 1B/1D, or 5-HT1B/1D) receptor agonist, decreases CGRP1 expression via the induction of dual-specificity protein phosphatase 1 (DUSP1), attenuated JNK activity and mitigated pathogenic AR-mediated neuronal damage in cellular and mouse SBMA models. 
Trophic support: one of the main aims of SBMA therapy is to strengthen muscle activity. For this reason, $\beta$-agonist drugs have been considered as promoter of muscle anabolism increasing muscle mass in mouse models [93]. A pilot study on clenbuterol, a well-known $\beta 2$-agonist, demonstrated an improvement in muscle force and resistance that persisted after 12 months of clinical monitoring but was associated with a significant increase in CPK serum levels [94]. Interesting data from mouse models support the hypothesis that clenbuterol ameliorates satellite cells functions in SBMA inducing myoblast fusion and muscle morphology [65] [95], anyway further randomized controlled clinical trials are warranted to confirm the efficacy of clenbuterol in SBMA.

Physical support: Exercise, as a treatment for neuromuscular diseases, has received growing attention in the last two decades and new evidence has revoked the older notion that muscle contractions may accelerate the disease process [96]. Available studies suggest that conventional aerobic training at mild to moderate intensity has no clear effect on motor capabilities in SBMA and may even promote fatigue [97]. Similar results are observed in patients with spinal muscular atrophy (SMA) type III: training improves oxidative capacity, but not function [98]. These observations point to an exercise-induced fatigue in motor neuron diseases, which may relate to a neural fatigue when fewer numbers of motor neurons, each of which have a larger motor unit size than normal, have to support sustained muscle contractions. Types of exercise other than prolonged aerobic training should be considered in SBMA patients and, in this regard, it is encouraging that high intensity aerobic training seems to be much better tolerated and associated with improvements in fitness [96]. This type of exercise therefore needs much more investigation and a dedicated clinical trial is ongoing (NCT02024932).

Recently, a sequence of head-lift exercises has been proposed as it seems to ameliorate swallowing dysfunction [99]. This hypothesis has been tested in six patients with good results but needs to be confirmed in larger and longitudinal trials.

Clinical trials. As stated above, in the past years several clinical trials have been conducted in SBMA patients, studying the possible efficacy of both pharmacological and physical therapies. At the time of this writing, the clinicaltrials.gov website (www.clinicaltrials.gov) identifies two ongoing interventional trials in SBMA. One is a trial (NCT02024932) of the effect of high intensity training in patients with SBMA. The 
other (NCT02024932) is a double-blind placebo-controlled phase I/II (safety, tolerability, and efficacy) trial of an experimental compound BVS857 sponsored by the Swiss pharmaceutical company Novartis.

To date, none of the interventions that were tested have translated into approved therapeutic or preventive options for SBMA patients and the results may appear sobering. This situation may depend on different reasons: being SBMA a rare disease, setting up cohorts that are adequately sized for full-fledged clinical trials, i.e., comprising up to several hundreds of patients, may be a daunting task and the only way to fully realize this is to connect different SBMA clinics and to thus create a network of international collaborations. Moreover, disease phenotype and progression may be extremely variable between SBMA patients. The confounding effect of the clinical heterogeneity is than accentuated by the lack of sensitive and standardized outcome measures in such a slow progressing disease. In part because of its low incidence and prevalence, most of outcome measures have not been specifically validated in SBMA. It is therefore unfortunate, but not surprising, that the completed SBMA trials have relied on different primary outcomes. This lack of harmonization significantly compromises the comparability of study results.

A European NeuroMuscular Workshop on SBMA took place in March 2015, and an agreement was reached among several centers to use a common protocol to follow patients toward the goal of building an International SBMA Registry [100] [101].

\section{Biomarkers}

As stated above, there is a critical need for biomarker discovery and validation in SBMA in order to provide sensitive outcome measures permitting quantification of disease progression in a smaller number of participants and over a shorter period of time than traditional clinical outcomes. Biomarkers can be grouped as either "dry biomarkers" or "wet biomarkers". "Dry biomarkers" rely on functional scales, performed tasks, electrophysiology and imaging. Wet biomarkers are biological substances that are measured in a body fluid.

Within the "dry biomarkers" some efforts have been made to define a reliable functional score for SBMA patients [102]: first of all, the 6-min walk test is a global measure that has the advantage that it assesses fatigue, a prominent symptom in SBMA. It has been shown to be reliable and to change significantly over a one year period [103]. Recently a specific functional scale has been proposed [104], which is an adaptation 
of ALSFRS-r, the gold standard functional scale used in amyotrophic lateral sclerosis. The scale has been validated in a population of Japanese and American patients and in an Italian population as well [105]. It includes novel items regarding bulbar and truncal functions and could be SBMA-FRS a sensitive clinical measure to detect disease progression over time. To evaluate motor function, the Adult Myopathy Assessment Tool (AMAT) has been proposed. It includes seven timed functional tasks and six endurance tasks which seems to correlate well with other physical assessments, such as quantitative muscle testing (QMT), gait speed, and physical quality of life [106]. Grip strength is a parameter used in different neuromuscular diseases to easily depict muscle weakness progression. Significant changes in grip strength have been observed in a 3-year longitudinal study of SBMA patients [107] but no significant change over a one year period was detected in another study [103]. A recent study evaluated the measure of tongue pressure using an intraoral pressure probe [108]. This measure seems to be reliable but longitudinal studies are required to confirm its use as biomarker of disease progression.

Electrophysiological measures, such as Motor Unit Number Estimation (MUNE), motor unit number index (MUNIX) or electrical impedance myography that are proposed as progression biomarkers in MNDs may also be applicable in the context of SBMA [102] [109]. Muscle MRI has the potential to be a good biomarker of disease progression in SBMA [102]. A small study on muscle MRI showed that imaging can indeed be used to quantify muscle atrophy and detect hyperintensities in SBMA patients [110]. Future, longitudinal studies are also needed to investigate the value of spinal cord imaging, especially since the measure of spinal cord atrophy has been demonstrated to be a sensitive index of motor neuron loss both in amyotrophic lateral sclerosis [111] [112] and in SMA [113].

Many potential "wet" biomarkers have been investigated in SBMA. Creatinine, a marker of muscle mass and metabolism, showed significant change over a three-year period [107]. Similarly, urinary 8hydroxydeoxyguanosine (8-OHdG), a marker of oxidative DNA damage, also showed significant change over a two-year period in SBMA patients [114]. It remains to be established whether these markers are more sensitive than classic clinical measures when there are shorter intervals between assessments. 


\section{Conclusion}

SBMA is a rare and complex syndrome, presenting not only with a well-known neuromuscular phenotype, but also with systemic and neuropsychological symptoms. In the last years, knowledge about clinical presentation and pathogenesis has widely improved leading to more effective diagnostic protocols and to better patients' management. Clinical trials are being organized but, the disease being extremely rare and slow progressing, identification of reliable biomarkers is challenging, making the struggle to find new drugs even more difficult. For these reasons, creation of a European network aimed at sharing common evaluation protocols is warranted. Recently, the bases for a European registry of the disease have been posed, which could be the first step leading to quick biomarkers identification and to development of new therapeutic approaches [101]. 


\section{References}

1. Fratta P, Nirmalananthan N, Masset L, Skorupinska I, Collins T, Cortese A, et al. Correlation of clinical and molecular features in spinal bulbar muscular atrophy. Neurology. 2014;82(23):2077-84.

2. Fischbeck KH. Kennedy disease. J Inherit Metab Dis. 1997;20(2):152-8.

3. Lund a, Udd B, Juvonen V, Andersen PM, Cederquist K, Davis M, et al. Multiple founder effects in spinal and bulbar muscular atrophy (SBMA, Kennedy disease) around the world. Eur J Hum Genet. 2001;9(6):431-6.

4. Tanaka F, Doyu M, Ito Y, Matsumoto M, Mitsuma T, Abe K, et al. Founder effect in spinal and bulbar muscular atrophy (SBMA). Hum Mol Genet 1996;5(9):1253-7.

5. Udd B, Juvonen V, Hakamies L, Nieminen A, Wallgren-Pettersson C, Cederquist K, et al. High prevalence of Kennedy's disease in Western Finland -- is the syndrome underdiagnosed? Acta Neurol Scand 1998; 98(2):128-33.

6. Katsuno M, Tanaka F, Adachi H, Banno H, Suzuki K, Watanabe H, et al. Pathogenesis and therapy of spinal and bulbar muscular atrophy (SBMA). Prog Neurobiol; 2012;99(3):246-56.

7. Chahin N, Klein C, Mandrekar J, Sorenson E. Natural history of spinal-bulbar muscular atrophy. Neurology. 2008;70(21):1967-71.

8. Guidetti D, Sabadini R, Ferlini A, Torrente I. Epidemiological survey of X-linked bulbar and spinal muscular atrophy, or Kennedy disease, in the province of Reggio Emilia, Italy. Eur J Epidemiol 2001;17(6):587-91.

9. Sperfeld AD, Karitzky J, Brummer D, Schreiber H, Häussler J, Ludolph AC, et al. X-linked bulbospinal neuronopathy: Kennedy disease. Arch Neurol 2002;59(12):1921-6.

10. Atsuta N, Watanabe H, Ito M, Banno H, Suzuki K, Katsuno M, et al. Natural history of spinal and bulbar muscular atrophy (SBMA): A study of 223 Japanese patients. Brain. 2006;129(6):1446-55.

11. Finsterer J, Soraru G. Onset Manifestations of Spinal and Bulbar Muscular Atrophy (Kennedy's Disease). J Mol Neurosci 2016;58(3):321-9.

12. Aicua I, Verhagen O, Arenaza N, Cubo E. Head and Arm Tremor in X-linked Spinal and Bulbar Muscular Atrophy. Tremor Other Hyperkinet Mov (N Y) 2014;4:265.

13. Dias FA, Munhoz RP, Raskin S, Werneck LC, Teive HA. Tremor in X-linked recessive spinal and 
bulbar muscular atrophy (Kennedy’s disease). Clin (Sao Paulo) 2011;66(6):955-7.

14. Nishiyama A, Sugeno N, Tateyama M, Nishiyama S, Kato M, Aoki M. Postural leg tremor in Xlinked spinal and bulbar muscular atrophy. J Clin Neurosci; 2014;21(5):799-802.

15. Finsterer J. Perspectives of Kennedy’s disease. J Neurol Sci; 2010;298(1-2):1-10.

16. Larsen K, Smith TA. "Jaw drop" as an atypical manifestation of Kennedy’s disease. Ugeskr Laeger 2005;167(35):3310-1.

17. Sumner CJ, Fischbeck KH. Jaw drop in Kennedy's disease. Neurology. 2002;59(9):1471-2.

18. Harding AE, Thomas PK, Baraitser M, Bradbury PG, Morgan-Hughes JA, Ponsford JR. X-linked recessive bulbospinal neuronopathy: a report of ten cases. J Neurol Neurosurg Psychiatry 1982;45(11):1012-9.

19. Sperfeld A-D, Hanemann CO, Ludolph AC, Kassubek J. Laryngospasm: an underdiagnosed symptom of X-linked spinobulbar muscular atrophy. Neurology 2005;64(4):753-4.

20. Tanaka S, Banno H, Katsuno M, Suzuki K, Suga N, Hashizume A, et al. Distinct acoustic features in spinal and bulbar muscular atrophy patients with laryngospasm. J Neurol Sci; 2014;337(1-2):193200.

21. Warnecke T, Oelenberg S, Teismann I, Suntrup S, Hamacher C, Young P, et al. Dysphagia in Xlinked bulbospinal muscular atrophy (Kennedy disease). Neuromuscul Disord 2009;19(10):704-8.

22. Antonini G, Gragnani F, Romaniello A, Pennisi EM, Morino S, Ceschin V, et al. Sensory involvement in spinal-bulbar muscular atrophy (Kennedy's disease). Muscle and Nerve. $2000 ; 23(2): 252-8$.

23. Manganelli F, Iodice V, Provitera V, Pisciotta C, Nolano M, Perretti A, et al. Small-fiber involvement in spinobulbar muscular atrophy (Kennedy’s disease). Muscle Nerve 2007;36(6):816-20.

24. Adachi H, Katsuno M, Minamiyama M, Waza M, Sang C, Nakagomi Y, et al. Widespread nuclear and cytoplasmic accumulation of mutant androgen receptor in SBMA patients. Brain. 2005;128(3):659-70.

25. Li M, Miwa S, Kobayashi Y, Merry DE, Yamamoto M, Tanaka F, et al. Nuclear inclusions of the androgen receptor protein in spinal and bulbar muscular atrophy. Ann Neurol 1998;44(2):249-54.

26. Thomas PS, Fraley GS, Damien V, Woodke LB, Zapata F, Sopher BL, et al. Loss of endogenous 
androgen receptor protein accelerates motor neuron degeneration and accentuates androgen insensitivity in a mouse model of X-linked spinal and bulbar muscular atrophy. Hum Mol Genet. 2006;15(14):2225-38.

27. Li X-H, Zhuang J-J, Xie Q-Y, Li A-P, Liang X-L, Feng Y-Q, et al. Clinical manifestations and molecular genetics of spinal bulbar muscular atrophy: report of 5 cases. Zhonghua Yi Xue Za Zhi 2007;87(23):1611-5.

28. Battaglia F, Le Galudec V, Cossee M, Tranchant C, Warter JM, Echaniz-Laguna A. Kennedy's Disease Initially Manifesting as an Endocrine Disorder. J Clin Neuromuscul Dis 2003;4(4):165-7.

29. Dejager S, Bry-Gauillard H, Bruckert E, Eymard B, Salachas F, LeGuern E, et al. A comprehensive endocrine description of Kennedy's disease revealing androgen insensitivity linked to CAG repeat length. J Clin Endocrinol Metab. 2002;87(8):3893-901.

30. Querin G, Bertolin C, Da Re E, Volpe M, Zara G, Pegoraro E, et al. Non-neural phenotype of spinal and bulbar muscular atrophy: results from a large cohort of Italian patients. J Neurol Neurosurg Psychiatry 2015;jnnp-2015-311305.

31. Araki A, Katsuno M, Suzuki K, Banno H, Suga N, Hashizume A, et al. Brugada syndrome in spinal and bulbar muscular atrophy. Neurology. 2014;82(20):1813-21.

32. Querin G, Melacini P, D’Ascenzo C, Morandi L, Mazzini L, Silani V, et al. No evidence of cardiomyopathy in spinal and bulbar muscular atrophy. Acta Neurol Scand. 2013;128(6):30-2.

33. Yu Z, Dadgar N, Albertelli M, Gruis K, Jordan C, Robins DM, et al. Androgen-dependent pathology demonstrates myopathic contribution to the Kennedy disease phenotype in a mouse knock-in model. J Clin Invest 2006;116(10):2663-72.

34. Kessler H, Prudlo J, Kraft S, Supprian T. Dementia of frontal lobe type in Kennedy's disease. Amyotroph Lateral Scler Other Motor Neuron Disord 2005;6(4):250-3.

35. Mirowska-Guzel D, Seniow J, Sułek A, Leśniak M, Członkowska A. Are cognitive and behavioural deficits a part of the clinical picture in Kennedy's disease? A case study. Neurocase 2009;15(4):3327.

36. Guidetti D, Vescovini E, Motti L, Ghidoni E, Gemignani F, Marbini A, et al. X-linked bulbar and spinal muscular atrophy, or Kennedy disease: clinical, neurophysiological, neuropathological, 
neuropsychological and molecular study of a large family. J Neurol Sci 1996;135(2):140-8.

37. Soukup GR, Sperfeld AD, Uttner I, Karitzky J, Ludolph AC, Kassubek J, et al. Frontotemporal cognitive function in X-linked spinal and bulbar muscular atrophy (SBMA): A controlled neuropsychological study of 20 patients. J Neurol. 2009;256(11):1869-75.

38. Di Rosa E, Sorarù G, Kleinbub JR, Calvo V, Vallesi A, Querin G, et al. Theory of mind, empathy and neuropsychological functioning in X-linked spinal and bulbar muscular atrophy: a controlled study of 20 patients. J Neurol 2015;262(2):394-401.

39. Lai T, Soong B, Chen J, Chen Y, Lai K. Multimodal Evoked Potentials of Kennedy's Disease. $2007 ; 328-32$.

40. Kassubek J, Juengling FD, Sperfeld A-D. Widespread white matter changes in Kennedy disease: a voxel based morphometry study. J Neurol Neurosurg Psychiatry 2007;78(11):1209-12.

41. Unrath A, Müller H-P, Riecker A, Ludolph AC, Sperfeld A-D, Kassubek J. Whole brain-based analysis of regional white matter tract alterations in rare motor neuron diseases by diffusion tensor imaging. Hum Brain Mapp 2010;31(11):1727-40.

42. Pieper CC, Konrad C, Sommer J, Teismann I, Schiffbauer H. Structural changes of central white matter tracts in Kennedy's disease - a diffusion tensor imaging and voxel-based morphometry study. Acta Neurol Scand. 2013;127(5):323-8.

43. Lai T-H, Liu R-S, Yang B-H, Wang P-S, Lin K-P, Lee Y-C, et al. Cerebral involvement in spinal and bulbar muscular atrophy (Kennedy's disease): a pilot study of PET. J Neurol Sci 2013;335(12):139-44.

44. Georgiou I, Sermon K, Lissens W, De Vos A, Platteau P, Lolis D, et al. Preimplantation genetic diagnosis for spinal and bulbar muscular atrophy (SBMA). Hum Genet 2001;108(6):494-8.

45. Mariotti C, Castellotti B, Pareyson D, Testa D, Eoli M, Antozzi C, et al. Phenotypic manifestations associated with CAG-repeat expansion in the androgen receptor gene in male patients and heterozygous females: A clinical and molecular study of 30 families. Neuromuscul Disord. 2000;10(6):391-7.

46. Sorarù G, D’Ascenzo C, Polo A, Palmieri A, Baggio L, Vergani L, et al. Spinal and bulbar muscular atrophy: skeletal muscle pathology in male patients and heterozygous females. J Neurol Sci 
2008;264(1-2):100-5.

47. Takeyama KI, Ito S, Yamamoto A, Tanimoto H, Furutani T, Kanuka H, et al. Androgen-dependent neurodegeneration by polyglutamine-expanded human androgen receptor in Drosophila. Neuron. 2002;35(5):855-64.

48. Walcott JL, Merry DE. Ligand promotes intranuclear inclusions in a novel cell model of spinal and bulbar muscular atrophy. J Biol Chem. 2002;277(52):50855-9.

49. Katsuno M, Adachi H, Kume A, Li M, Nakagomi Y, Niwa H, et al. Testosterone reduction prevents phenotypic expression in a transgenic mouse model of spinal and bulbar muscular atrophy. Neuron. 2002;35(5):843-54.

50. Poletti A. The polyglutamine tract of androgen receptor: from functions to dysfunctions in motor neurons. Front Neuroendocrinol 2004;25(1):1-26.

51. Abel a, Walcott J, Woods J, Duda J, Merry DE. Expression of expanded repeat androgen receptor produces neurologic disease in transgenic mice. Hum Mol Genet 2001;10(2):107-16.

52. Stenoien DL, Cummings CJ, Adams HP, Mancini MG, Patel K, DeMartino GN, et al. Polyglutamineexpanded androgen receptors form aggregates that sequester heat shock proteins, proteasome components and SRC-1, and are suppressed by the HDJ-2 chaperone. Hum Mol Genet 1999; 8(5):731-41.

53. Taylor JP, Tanaka F, Robitschek J, Sandoval CM, Taye A, Markovic-Plese S, et al. Aggresomes protect cells by enhancing the degradation of toxic polyglutamine-containing protein. Hum Mol Genet 2003;12(7):749-57.

54. Ranganathan S, Harmison GG, Meyertholen K, Pennuto M, Burnett BG, Fischbeck KH. Mitochondrial abnormalities in spinal and bulbar muscular atrophy. Hum Mol Genet. 2009;18(1):2742.

55. Borgia D, Malena A, Spinazzi M, Andrea Desbats M, Salviati L, Russell AP, et al. Increased mitophagy in the skeletal muscle of spinal and bulbar muscular atrophy patients. Hum Mol Genet. 2017 Jan 13. pii: ddx019. doi: 10.1093/hmg/ddx019.

56. Mariotti C, Castellotti B, Pareyson D, Testa D, Eoli M, Antozzi C, et al. Phenotypic manifestations associated with CAG-repeat expansion in the androgen receptor gene in male patients and 
heterozygous females: a clinical and molecular study of 30 families. Neuromuscul Disord 2000; 10(6):391-7.

57. Chahin N, Sorenson EJ. Serum creatine kinase levels in spinobulbar muscular atrophy and amyotrophic lateral sclerosis. Muscle Nerve 2009;40(1):126-9.

58. Sorenson EJ, Klein CJ. Elevated creatine kinase and transaminases in asymptomatic SBMA. Amyotroph Lateral Scler 2007;8(1):62-4.

59. Chevalier-Larsen ES, O’Brien CJ, Wang H, Jenkins SC, Holder L, Lieberman AP, et al. Castration restores function and neurofilament alterations of aged symptomatic males in a transgenic mouse model of spinal and bulbar muscular atrophy. J Neurosci 2004;24(20):4778-86.

60. Palazzolo I, Stack C, Kong L, Musaro A, Adachi H, Katsuno M, et al. Overexpression of IGF-1 in Muscle Attenuates Disease in a Mouse Model of Spinal and Bulbar Muscular Atrophy. Neuron; 2009; 63(3):316-28.

61. Giorgetti E, Lieberman AP. Polyglutamine androgen receptor-mediated neuromuscular disease. Cell Mol Life Sci 2016;73(21):3991-9.

62. Monks DA, Johansen JA, Mo K, Rao P, Eagleson B, Yu Z, et al. Overexpression of wild-type androgen receptor in muscle recapitulates polyglutamine disease. Proc Natl Acad Sci U S A 2007;104(46):18259-64.

63. Sinha-Hikim I, Taylor WE, Gonzalez-Cadavid NF, Zheng W, Bhasin S. Androgen receptor in human skeletal muscle and cultured muscle satellite cells: up-regulation by androgen treatment. J Clin Endocrinol Metab 2004;89(10):5245-55.

64. Sinha-Hikim I, Artaza J, Woodhouse L, Gonzalez-Cadavid N, Singh AB, Lee MI, et al. Testosteroneinduced increase in muscle size in healthy young men is associated with muscle fiber hypertrophy. Am J Physiol Endocrinol Metab. 2002;283(1):E154-64.

65. Malena A, Pennuto M, Tezze C, Querin G, D’Ascenzo C, Silani V, et al. Androgen-dependent impairment of myogenesis in spinal and bulbar muscular atrophy. Acta Neuropathol. 2013;126(1):109-21.

66. Mo K, Razak Z, Rao P, Yu Z, Adachi H, Katsuno M, et al. Microarray analysis of gene expression by skeletal muscle of three mouse models of Kennedy disease/spinal bulbar muscular atrophy. PLoS 
One. 2010;5(9):1-8.

67. Yu Z, Wang AM, Robins DM, Lieberman AP. Altered RNA splicing contributes to skeletal muscle pathology in Kennedy disease knock-in mice. Dis Model Mech. 2009;2(9-10):500-7.

68. Sopher BL, Thomas PS, LaFevre-Bernt MA, Holm IE, Wilke SA, Ware CB, et al. Androgen receptor YAC transgenic mice recapitulate SBMA motor neuronopathy and implicate VEGF164 in the motor neuron degeneration. Neuron 2004;41(5):687-99.

69. Hughes IA, Lim HN, Martin H, Mongan NP, Dovey L, Ahmed SF, et al. Developmental aspects of androgen action. Mol Cell Endocrinol 2001;185(1-2):33-41.

70. Palazzolo I, Burnett BG, Young JE, Brenne PL, La Spada AR, Fischbeck KH, et al. Akt blocks ligand binding and protects against expanded polyglutamine androgen receptor toxicity. Hum Mol Genet 2007;16(13):1593-603.

71. Bodine SC, Latres E, Baumhueter S, Lai VK, Nunez L, Clarke BA, et al. Identification of ubiquitin ligases required for skeletal muscle atrophy. Science 2001;294(5547):1704-8.

72. Yu Z, Wang AM, Adachi H, Katsuno M, Sobue G, Yue Z, et al. Macroautophagy is regulated by the UPR-mediator CHOP and accentuates the phenotype of SBMA mice. PLoS Genet. 2011;7(10).

73. Rocchi A, Pennuto M. New routes to therapy for spinal and bulbar muscular atrophy. J Mol Neurosci. 2013;50(3):514-23.

74. Katsuno M, Adachi H, Doyu M, Minamiyama M, Sang C, Kobayashi Y, et al. Leuprorelin rescues polyglutamine-dependent phenotypes in a transgenic mouse model of spinal and bulbar muscular atrophy. Nat Med 2003;9(6):768-73.

75. Fernández-Rhodes LE, Kokkinis AD, White MJ, Watts CA, Auh S, Jeffries NO, et al. Efficacy and safety of dutasteride in patients with spinal and bulbar muscular atrophy: a randomised placebocontrolled trial. Lancet Neurol 2011;10(2):140-7.

76. Baniahmad A. Inhibition of the Androgen Receptor by Antiandrogens in Spinobulbar Muscle Atrophy. J Mol Neurosci 2016;58(3):343-7.

77. Minamiyama M, Katsuno M, Adachi H, Waza M, Sang C, Kobayashi Y, et al. Sodium butyrate ameliorates phenotypic expression in a transgenic mouse model of spinal and bulbar muscular atrophy. Hum Mol Genet 2004;13(11):1183-92. 
78. Miyazaki Y, Adachi H, Katsuno M, Minamiyama M, Jiang Y-M, Huang Z, et al. Viral delivery of miR-196a ameliorates the SBMA phenotype via the silencing of CELF2. Nat Med; 2012;18(7):113641.

79. Nedelsky NB, Pennuto M, Smith RB, Palazzolo I, Moore J, Nie Z, et al. Native functions of the androgen receptor are essential to pathogenesis in a drosophila model of spinobulbar muscular atrophy. Neuron.; 2010;67(6):936-52.

80. Orr CR, Montie HL, Liu Y, Bolzoni E, Jenkins SC, Wilson EM, et al. An interdomain interaction of the androgen receptor is required for its aggregation and toxicity in spinal and bulbar muscular atrophy. J Biol Chem. 2010;285(46):35567-77.

81. Johansen JA, Troxell-Smith SM, Yu Z, Mo K, Monks DA, Lieberman AP, et al. Prenatal flutamide enhances survival in a myogenic mouse model of spinal bulbar muscular atrophy. Neurodegener Dis. 2010;8(1-2):25-34.

82. Palazzolo I, Burnett BG, Young JE, Brenne PL, La Spada AR, Fischbeck KH, et al. Akt blocks ligand binding and protects against expanded polyglutamine androgen receptor toxicity. Hum Mol Genet. 2007;16(13):1593-603.

83. Kobayashi Y, Kume A, Li M, Doyu M, Hata M, Ohtsuka K, et al. Chaperones Hsp70 and Hsp40 suppress aggregate formation and apoptosis in cultured neuronal cells expressing truncated androgen receptor protein with expanded polyglutamine tract. J Biol Chem. 2000;275(12):8772-8.

84. Bailey CK, Andriola IFM, Kampinga HH, Merry DE. Molecular chaperones enhance the degradation of expanded polyglutamine repeat androgen receptor in a cellular model of spinal and bulbar muscular atrophy. Hum Mol Genet. 2002;11(5):515-23.

85. Adachi H, Katsuno M, Minamiyama M, Sang C, Pagoulatos G, Angelidis C, et al. Heat shock protein 70 chaperone overexpression ameliorates phenotypes of the spinal and bulbar muscular atrophy transgenic mouse model by reducing nuclear-localized mutant androgen receptor protein. J Neurosci. 2003;23(6):2203-11.

86. Pearl LH, Prodromou C, Workman P. The Hsp90 molecular chaperone: an open and shut case for treatment. Biochem J 2008;410(3):439-53.

87. Kieran D, Kalmar B, Dick JRT, Riddoch-Contreras J, Burnstock G, Greensmith L. Treatment with 
arimoclomol, a coinducer of heat shock proteins, delays disease progression in ALS mice. Nat Med 2004;10(4):402-5.

88. Malik B, Nirmalananthan N, Gray AL, La Spada AR, Hanna MG, Greensmith L. Co-induction of the heat shock response ameliorates disease progression in a mouse model of human spinal and bulbar muscular atrophy: Implications for therapy. Brain. 2013;136(3):926-43.

89. Ravikumar B, Duden R, Rubinsztein DC. Aggregate-prone proteins with polyglutamine and polyalanine expansions are degraded by autophagy. Hum Mol Genet 2002;11(9):1107-17.

90. Chevalier-Larsen ES, Merry DE. Testosterone treatment fails to accelerate disease in a transgenic mouse model of spinal and bulbar muscular atrophy. Dis Model Mech 2012;5(1):141-5.

91. Montie HL, Merry DE. Autophagy and access. Autophagy. 2009;5(8):1194-7.

92. Minamiyama M, Katsuno M, Adachi H, Doi H, Kondo N, Iida M, et al. Naratriptan mitigates CGRP1-associated motor neuron degeneration caused by an expanded polyglutamine repeat tract. Nat Med; 2012;18(10):1531-8.

93. Spann C, Winter ME. Effect of clenbuterol on athletic performance. Ann Pharmacother 1995;29(1):75-7.

94. Querin G, D’Ascenzo C, Peterle E, Ermani M, Bello L, Melacini P, et al. Pilot trial of clenbuterol in spinal and bulbar muscular atrophy. Neurology. 2013;80(23):2095-8.

95. Milioto C, Malena A, Maino E, Polanco MJ, Marchioretti C, Borgia D, et al. Beta-agonist stimulation ameliorates the phenotype of spinal and bulbar muscular atrophy mice and patient-derived myotubes. Sci Rep. 2017 Jan 24;7:41046. doi: 10.1038/srep41046.

96. Dahlqvist JR, Vissing J. Exercise Therapy in Spinobulbar Muscular Atrophy and Other Neuromuscular Disorders. J Mol Neurosci 2016;58(3):388-93.

97. Preisler N, Andersen G, Thogersen F, Crone C, Jeppesen TD, Wibrand F, et al. Effect of aerobic training in patients with spinal and bulbar muscular atrophy (Kennedy disease). Neurology. 2009;72(4):317-23.

98. Madsen KL, Hansen RS, Preisler N, Thøgersen F, Berthelsen MP, Vissing J. Training improves oxidative capacity, but not function, in spinal muscular atrophy type III. Muscle Nerve 2015;52(2):240-4. 
99. Mano T, Katsuno M, Banno H, Suzuki K, Suga N, Hashizume A, et al. Head Lift Exercise Improves Swallowing Dysfunction in Spinal and Bulbar Muscular Atrophy. Eur Neurol 2015;74(5-6):251-8.

100. Pennuto M, Greensmith L, Pradat P-F, Sorarù G. 210th ENMC International Workshop: Research and clinical management of patients with spinal and bulbar muscular atrophy, 27-29 March, 2015, Naarden, The Netherlands. Neuromuscul Disord 2015;25(10):802-12.

101. Pareyson D, Fratta P, Pradat P, Sorarù G, Finsterer J, Vissing J, et al. Towards a European Registry and Biorepository for Patients with Spinal and Bulbar Muscular Atrophy. 2016; J Mol Neurosci. 2016;58(3):394-400. doi: 10.1007/s12031-015-0704-5.

102. Pennuto M, Greensmith L, Pradat PF, Sorarù G, Baniahmad A, Basso M, et al. 210th ENMC International Workshop: Research and clinical management of patients with spinal and bulbar muscular atrophy, 27-29 March, 2015, Naarden, The Netherlands. Neuromuscul Disord 2015;25(10):802-12.

103. Takeuchi Y, Katsuno M, Banno H, Suzuki K, Kawashima M, Atsuta N, et al. Walking capacity evaluated by the 6-minute walk test in spinal and bulbar muscular atrophy. Muscle and Nerve. 2008;38(2):964-71.

104. Hashizume A, Katsuno M, Suzuki K, Banno H, Suga N, Mano T, et al. A functional scale for spinal and bulbar muscular atrophy: Cross-sectional and longitudinal study. Neuromuscul Disord; 2014;25(7):554-62.

105. Querin G, DaRe E, Martinelli I, Bello L, Bertolin C, Pareyson D, et al. Validation of the Italian version of the SBMA Functional Rating Scale as outcome measure. Neurol Sci 2016;37(11):1815-21.

106. Harris-Love MO, Fernandez-Rhodes L, Joe G, Shrader J a, Kokkinis A, La Pean Kirschner A, et al. Assessing function and endurance in adults with spinal and bulbar muscular atrophy: validity of the adult myopathy assessment tool. Rehabil Res Pract 2014;2014:873872.

107. Hashizume A, Katsuno M, Banno H, Suzuki K, Suga N, Mano T, et al. Longitudinal changes of outcome measures in spinal and bulbar muscular atrophy. Brain. 2012;135(9):2838-48.

108. Mano T, Katsuno M, Banno H, Suzuki K, Suga N, Hashizume A, et al. Tongue pressure as a novel biomarker of spinal and bulbar muscular atrophy. Neurology. 2014;82(3):255-62.

109. Suzuki K, Katsuno M, Banno H, Takeuchi Y, Kawashima M, Suga N, et al. The profile of motor unit 
number estimation (MUNE) in spinal and bulbar muscular atrophy. J Neurol Neurosurg Psychiatry. 2010;81(5):567-71.

110. Hamano T, Mutoh T, Hirayama M, Kawamura Y, Nagata M, Fujiyama J, et al. Muscle MRI findings of X-linked spinal and bulbar muscular atrophy. J Neurol Sci 2004;222(1-2):93-7.

111. Cohen-Adad J, Mendili M-M El, Morizot-Koutlidis R, Lehéricy S, Meininger V, Blancho S, et al. Involvement of spinal sensory pathway in ALS and specificity of cord atrophy to lower motor neuron degeneration. Amyotroph Lateral Scler Front Degener 2013;14(1):30-8.

112. El Mendili M-M, Cohen-Adad J, Pelegrini-Issac M, Rossignol S, Morizot-Koutlidis R, MarchandPauvert V, et al. Multi-Parametric Spinal Cord MRI as Potential Progression Marker in Amyotrophic Lateral Sclerosis. Raoul C, editor. PLoS One 2014;9(4):e95516.

113. El Mendili M-M, Lenglet T, Stojkovic T, Behin A, Guimarães-Costa R, Salachas F, et al. Cervical Spinal Cord Atrophy Profile in Adult SMN1-Linked SMA. PLoS One 2016;11(4):e0152439.

114. Mano T, Katsuno M, Banno H, Suzuki K, Suga N, Hashizume A, et al. Cross-sectional and longitudinal analysis of an oxidative stress biomarker for spinal and bulbar muscular atrophy. Muscle and Nerve. 2012;46(5):692-7.

Figure 1. Tongue atrophy in a patient with SBMA.

Figure 2. Molecular pathogenesis of SBMA. Under normal conditions, AR first interacts with its ligand (dihydrotestosterne, DHT) and then migrates into the cell nucleus, where it interacts with specific DNA sequences inducing transcription of androgens target genes. PolyQ-AR migrates as well into the nucleus after binding with testosterone. Anyway, once in the nucleus it is not able to correctly interact with AR target genes. Alteration of this pathway determines abnormal transcription and protein production of several genes which may lose their physiological function. At the same time, pathologic accumulation of the mutated protein may induce toxicity and neurodegeneration with a "gain of function" mechanism. 
Figure 3. Muscle matters and disease pathogenesis. In the pathogenesis of SBMA, damage to motor neurons can result both from cell-autonomous and non-cell-autonomous toxic processes, the last occurring in other cell types as for example skeletal muscle cells. These cells are highly androgens sensitive and may present alteration of several physiologic pathways after interaction with mutated polyQ-AR. Primary muscle dysfunction may alter motor neuron trophism, thus participating in neurodegeneration. Muscle dysfunction seems than to result both from primary muscle pathology and from neurogenic atrophy. The two mechanisms probably act together in the determination of disease phenotype. 


\begin{tabular}{|l|l|}
\hline $\begin{array}{l}\text { Other motor neuron } \\
\text { diseases }\end{array}$ & $\begin{array}{l}\text { ALS } \\
\text { ALS variants (flail arm and } \\
\text { flail leg syndromes, } \\
\text { progressive muscle atrophy) } \\
\text { SMA type III and IV }\end{array}$ \\
\hline $\begin{array}{l}\text { Neuromuscular junction } \\
\text { disorders }\end{array}$ & Myasthenia gravis \\
\hline Neuropathies & $\begin{array}{l}\text { CIDP } \\
\text { Hereditary motor neuropathies } \\
\text { (dHMN) }\end{array}$ \\
\hline Myopathies & $\begin{array}{l}\text { Polymyositis } \\
\text { Metabolic myopathies } \\
\text { IBM }\end{array}$ \\
\hline Endocrine disorders & $\begin{array}{l}\text { Hyper- or hypothyroidism } \\
\text { Hyperparathyroidism }\end{array}$ \\
\hline
\end{tabular}

Table 1. Differential diagnosis of SBMA.

Abbreviations: ALS: amyotrophic lateral sclerosis, CIDP: chronic inflammatory demyelinating neuropahy, IBM: inclusion body myositis, SMA: spinal muscular atrophy 


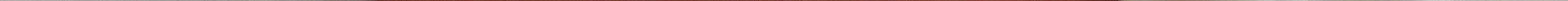




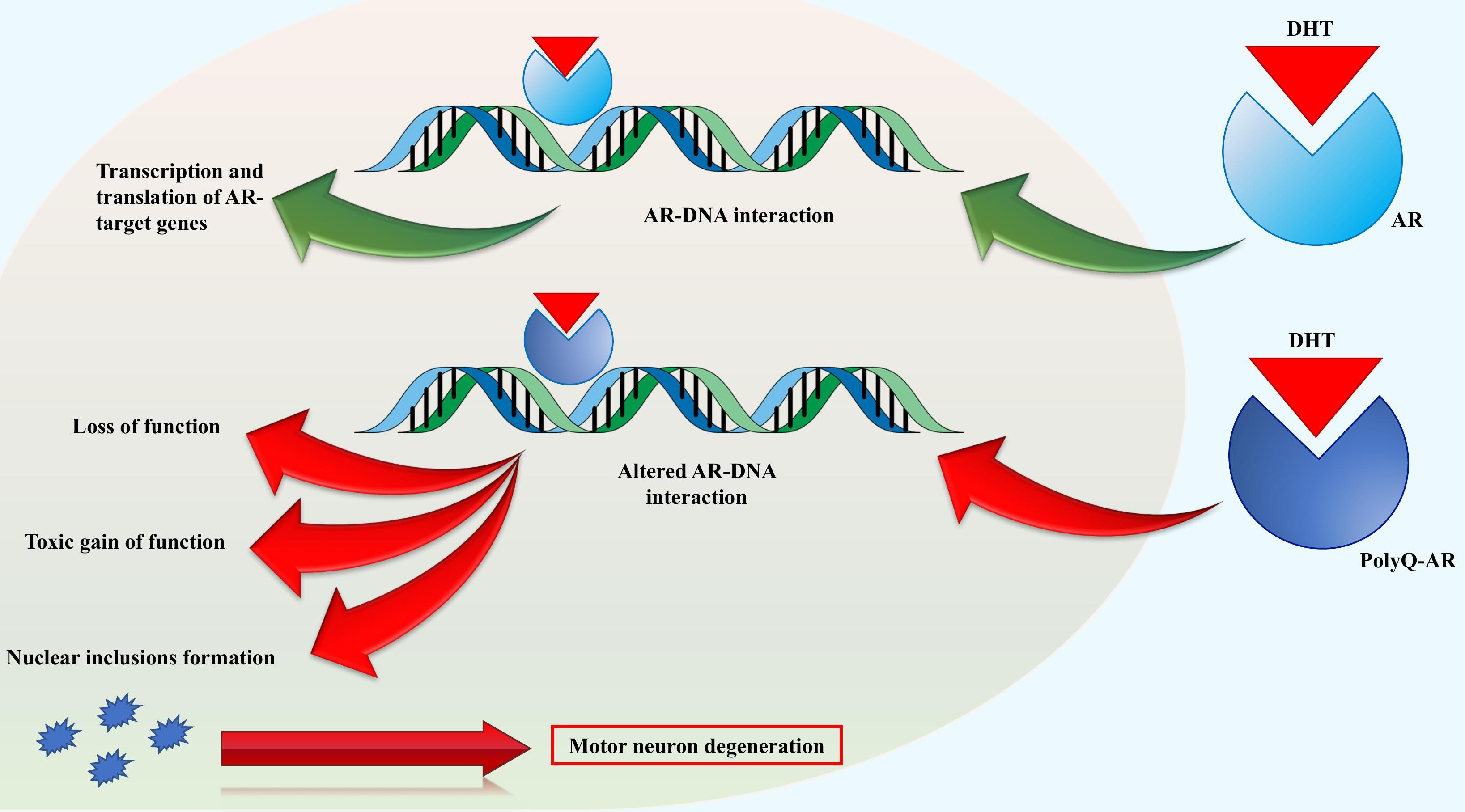



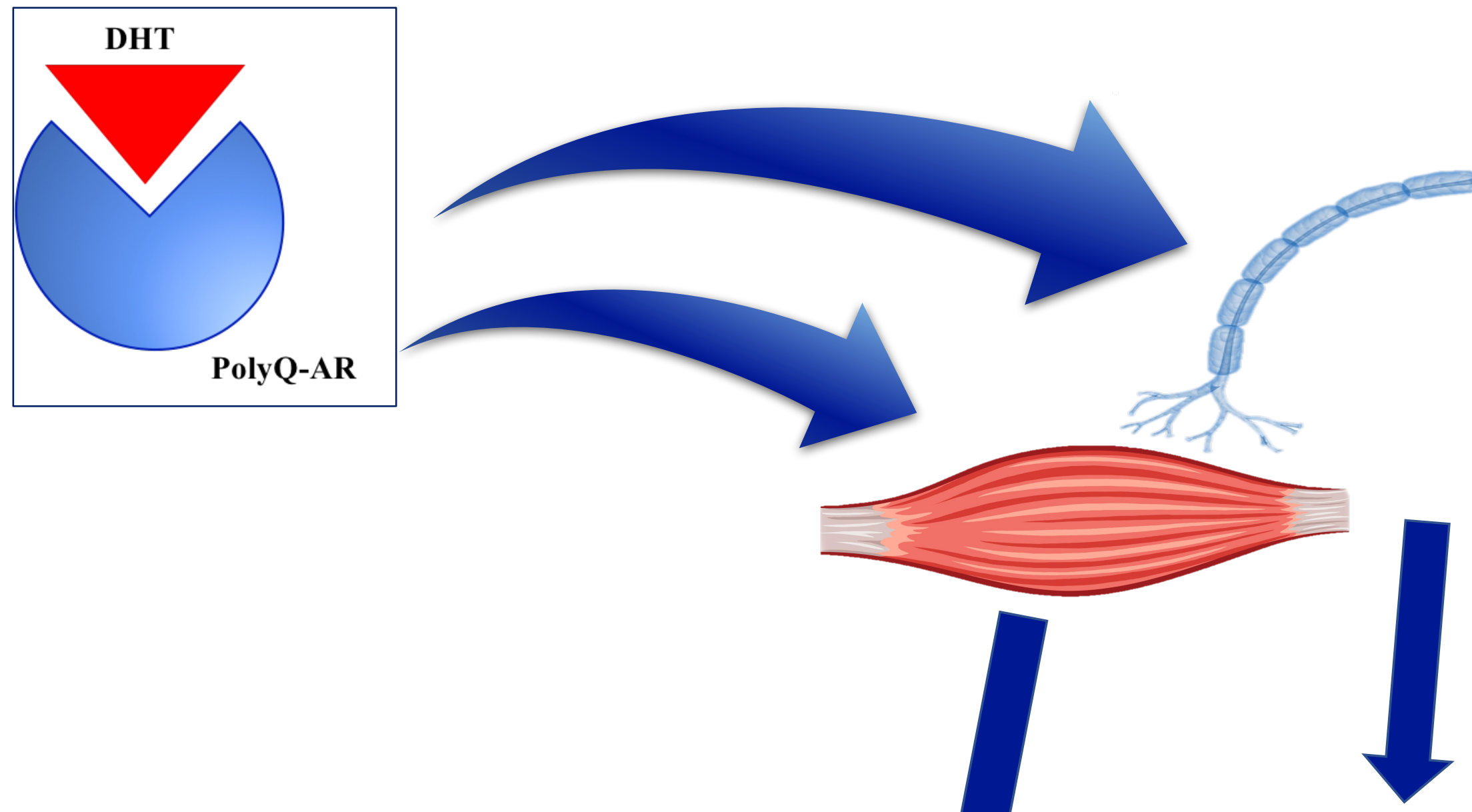

Altered neurotrophins
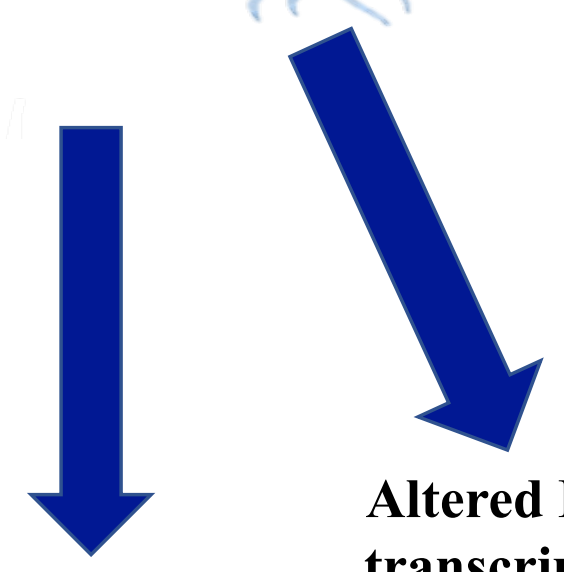

Altered RNA transcription

Altered RNA splicing

release

Altered satellite cells trophic support 